\title{
Effect of Growth Parameters on Composition Distribution in Superlattice-in-Well Structure by Submonolayer Deposition Technique
}

\author{
Guo-Zhi Jia ${ }^{a}$, Jiang-Hong Yao ${ }^{b}$, Yong-Chun $\mathrm{Shu}^{b}$, XiaO-Dong Xing ${ }^{b}$ And Biao Pi ${ }^{b}$ \\ ${ }^{a}$ Tianjin Institute of Urban Construction, Tianjin 300384, China \\ ${ }^{b}$ The Key Lab of Advanced Technique and Fabrication for Weak-Light Nonlinear Photonics Materials \\ Ministry of Education, TEDA Applied Physics School, Nankai University, Tianjin 300475, China
}

(Received February 16, 2009; in final form April 15, 2009)

\begin{abstract}
The superlattice-in-well structures were grown using a cycled submonolayer AlGaAs/GaAs deposition technique. The optical quality of Al-Ga interdiffusion in AlGaAs/GaAs superlattice was investigated by measuring the photoluminescence of samples grown at temperature from $610^{\circ} \mathrm{C}$ to $630^{\circ} \mathrm{C}$. Results show that $\mathrm{Al}$ composition can be modulated under some growth temperature or period. Effect of the growth interrupt in the growth process of superlattice on film optical quality is also discussed. Especially, the role played by the period of superlattice in the process of obtaining high quality film material with low composition is investigated in detail.
\end{abstract}

PACS numbers: 81.15.Hi, 68.55.Ln, 68.65.Fg, 68.65.Cd

\section{Introduction}

The potential of superlattice for the optoelectronic devices is due to the fact that energy band structure can be modulated by changing the period and distribution [1]. The high quality film for future optoelectronics devices requires the precise control of the thickness and composition $[2,3]$. Submonolayer deposition technique has attracted considerable investigation interest for implementing atom layer controllable growth [4]. At the same time, this approach results in a significant increase in component intermixing in the process of superlattice preparing due to the diffusion length shortening. Tremendous research effort has been focused to optimize the performance of electronic and optoelectronic devices by postgrowth diffusion technology [5-11], while less attention has been paid to in situ diffusion in superlattice with barrier layers of submonolayer thickness.

In this paper, the superlattice-in-well structures were grown using a cycled submonolayer AlGaAs/GaAs deposition technique. These quantum wells are composed of alternating $\mathrm{Al}_{x} \mathrm{Ga}_{1-x} \mathrm{As} / \mathrm{GaAs}$ layers with submonolayer thickness. The effect of growth temperature and period on composition was analyzed in detail. At the same time, $\mathrm{Al}-\mathrm{Ga}$ interdiffusion process in $\mathrm{AlGaAs} / \mathrm{GaAs}$ superlattice can be used to produce low content $\mathrm{Al}$ composition. It is possible for extending the technology to other complicated semiconductor systems.

\section{Experiment investigation}

The samples are prepared on the undoped GaAs (100) wafers in Riber32 compact 21 solid source MBE system equipped with a valved cracker cell for arsenic. We use the valve for a precise and immediate control of the arsenic flux. During growth of the AlGaAs layer, growth temperature is calibrated by infrared pyrometer. After loading into the growth chamber, the samples were slowly heated to $580^{\circ} \mathrm{C}$ to remove surface oxide. The GaAs buffer layer was grown at $580^{\circ} \mathrm{C}$ followed by a $15 \mathrm{~nm}$ thick AlAs/GaAs short-period superlattice (SL). The structure consisted of an undoped $0.2 \mu \mathrm{m}$ thick $\mathrm{Al}_{0.37} \mathrm{Ga}_{0.63}$ As core containing $7 \mathrm{~nm}$ thick quantum well. The part of quantum well was formed by alternate deposition submonolayer $\mathrm{Al}_{0.14} \mathrm{Ga}_{0.86}$ As and GaAs for several times. The core was sandwiched between a $1.5 \mu \mathrm{m}$ thick $\mathrm{Al}_{0.4} \mathrm{Ga}_{0.7} \mathrm{As}$ lower carrier confinement layer and a $0.9 \mu \mathrm{m}$ thick $\mathrm{Al}_{0.4} \mathrm{Ga}_{0.7}$ As super carrier confinement layer. The scheme of sample structure is shown in Fig. 1. The core structures were grown at the different growth temperature. In the photoluminescence (PL) measurement, samples were excited with the $\mathrm{Ar}^{+}$ laser $514.5 \mathrm{~nm}$ line. The PL spectra were detected with InGaAs detector. 


\begin{tabular}{|c|c|}
\hline \multicolumn{2}{|c|}{ GaAs cap $10 \mathrm{~nm}$} \\
\hline \multicolumn{2}{|c|}{$\mathrm{Al}_{0.4} \mathrm{Ga}_{0.6}$ As $900 \mathrm{~nm}$} \\
\hline \multicolumn{2}{|c|}{$\mathrm{Al}_{0.37} \mathrm{Ga}_{0.63} \mathrm{As} 200 \mathrm{~nm}$} \\
\hline $\mathrm{Al}_{0.14} \mathrm{Ga}_{0.86} \mathrm{As}$ & \multirow{2}{*}{$\times 30$} \\
\hline GaAs & \\
\hline \multicolumn{2}{|c|}{$\mathrm{Al}_{0.37} \mathrm{Ga}_{0.63} \mathrm{As} 200 \mathrm{~nm}$} \\
\hline \multicolumn{2}{|c|}{$\mathrm{Al}_{0.4} \mathrm{Ga}_{0.6} \mathrm{As} 1500 \mathrm{~nm}$} \\
\hline AlAs & \multirow{2}{*}{$\times 10$} \\
\hline GaAs & \\
\hline \multicolumn{2}{|c|}{ GaAs buffer $300 \mathrm{~nm}$} \\
\hline Sub. SI-Ga & $(100)$ \\
\hline
\end{tabular}

Fig. 1. Scheme of the superlattice-in-well structures. Sub SI-GaAs(100) represented semi-insulating $\operatorname{GaAs}(100)$ substrate.

\section{Results and discussion}

Figure 2 shows room temperature PL spectra of sample (a) (grown at $610^{\circ} \mathrm{C}$ ), sample (b) $\left(630^{\circ} \mathrm{C}\right.$ ) and sample (c) $\left(650^{\circ} \mathrm{C}\right)$, respectively. The excitation power of PL is the same for three samples. The full width at half maximum (FWHM) value is about $0.14 \mathrm{eV}$, which indicates good optical quality of the samples. The PL intensity of the samples (a) and (c) are slightly weaker than that of the sample (b). The increase in peak intensity at $630^{\circ} \mathrm{C}$ is probably due to the reduction of the nonradiative defects in the quantum well. For the high growth temperature $\left(650^{\circ} \mathrm{C}\right)$, the decrease in the peak intensity is due to the increase in the $\mathrm{Al}$ composition in the quantum well rather than the reduction of the quantum confinement. This is because the $\mathrm{Al}-\mathrm{Ga}$ interdiffusion was influenced little at the temperature near $650^{\circ} \mathrm{C}$, which had little effect to the variation of the quantum well width. That is to say, the quantum confinement of quantum well had little change as the growth temperature increases. The PL peak related to the superlattice-in-well of sample (c) is blue-shifted compared to sample (a) and (b). This could be ascribed to a decrease in the quantum well confined potential [12]. However, the Al-Ga interdiffusion does not take place between quantum wells and barriers even at the temperature $650^{\circ} \mathrm{C}$. This is because the intrinsic $\mathrm{GaAa} / \mathrm{AlGaAs}$ heterostructure shows the well thermal stability at the temperature $650^{\circ} \mathrm{C}[9,13]$. The Al-Ga interdiffusion coefficient is proportional to the concentration of the triply-charged column III vacancy $[9,11,14]$. Ga desorption is believed to enhance interdiffusion by introducing column III vacancy in GaAs layer growth process, at the same time, Ga concentration is decreased as the growth temperature increases, which can result in the increase in the $\mathrm{Al}$ concentration. The energy shift of PL emission can be attributed to $\mathrm{Al}$ concentration changing in the growth process of SL, not the changing of confinement energy of quantum well due to the diffusion between quantum well and barrier, as the growth temperature was elevated to $650^{\circ} \mathrm{C}$.

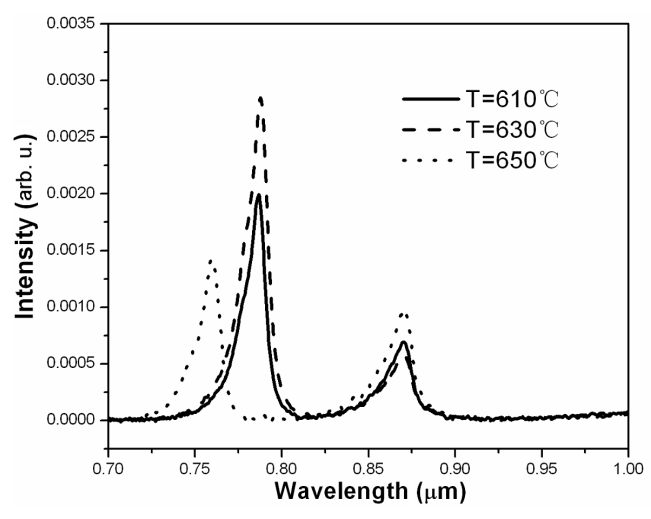

Fig. 2. The PL spectra of the SL samples with the different growth temperature: (a) $610^{\circ} \mathrm{C}$, (b) $630^{\circ} \mathrm{C}$, (c) $650^{\circ} \mathrm{C}$.

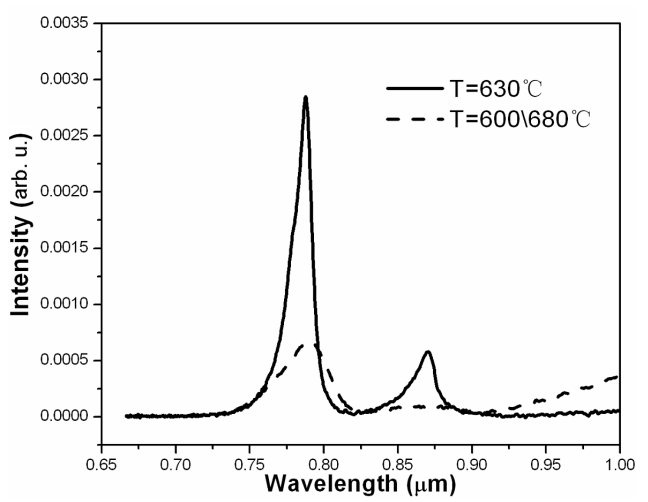

Fig. 3. The PL spectra of the SL samples with the same growth temperature. (d) $630^{\circ} \mathrm{C}$, with the alternate changing growth temperature, $\mathrm{GaAs}$ at $630^{\circ} \mathrm{C}$ and $\mathrm{AlGaAs}$ at $680^{\circ} \mathrm{C}$.

As we all know, high qualities of GaAs and AlGaAs layers are corresponding to the different optimal growth temperature, usually, GaAs to $580^{\circ} \mathrm{C}$ and $\mathrm{AlGaAs}$ to $680^{\circ} \mathrm{C}$. Thus, the effects of growth temperature on the optical quality of GaAs/AlGaAs SL are further investigated. When the substrate temperature is changed, a growth interruption occurs between GaAs and AlGaAs. Figure 3 shows the PL spectra of sample (d), which is compared with sample (c) result obtained at the same growth temperature. The FWHM of spectra grown with interruption were wider than those without interruption, which indicate that quantum well quality and the photoluminescence performance were not improved. Kinetic process of atom diffusion in the SL growth process with interruption can be significantly different with the growth process without interruption. In the growth process with interruption, the surface atom was relatively stable due to atom with enough long diffusion time. When the following layer was grown, the interdiffusion can be incomplete between the stable GaAs (AlGaAs) layer and surface AlGaAs (GaAs) layer. In the growth process with- 


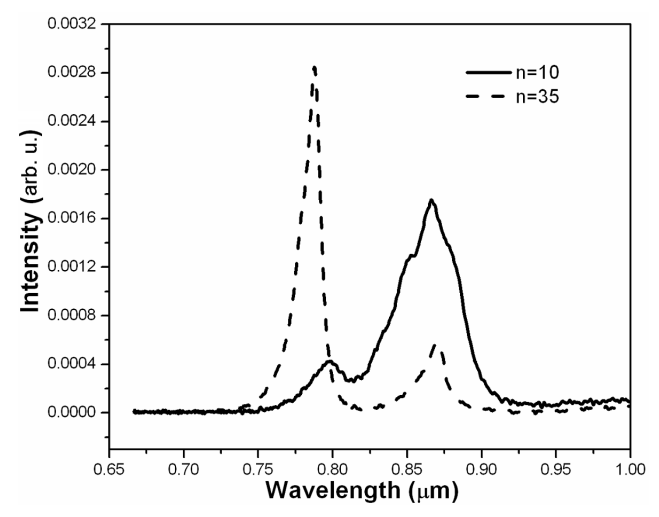

Fig. 4. The PL spectra of the SL samples with the different period, (e) 10, (c) 35, respectively.

out interruption, atom was unstable or metastable, the interdiffusion can take place easily between the unstable or metastable layers. The activation energy of the interdiffusion in the in situ growing process of SL, especially in unstable or metastable growth process (for example, continuous growth process) is smaller than that of stable growth process (for example, growth with interruption and ex situ postgrowth rapid annealing).

The room temperature of PL spectra for the samples grown for 10 and 35 periods are shown by dash line (sample (e)) and black line (sample (c)) in Fig. 4, respectively. The thickness of SL in sample (e) is the same to that in sample (c), equal to $7 \mathrm{~nm}$. The thickness of each GaAs and AlGaAs in SL decreases with the period increase. The diffusion length is shortened, giving rise to Al composition uniform distributions easily. It is to note that the PL peaks of the two samples have slightly different. The slight variation of the quantum well layer width could also result in the energy shift of the PL line during the two different growth processes. The specific influencing factors can need further investigation in the future.

\section{Conclusions}

In conclusion, we have studied the composition modulated via diffusion process in superlattice experimentally. This study may be applied to the fabrication of other group elements film materials with low composition. Results show Al composition can be modulated under some growth temperature or period. Especially, the role played by the period of superlattice in the process of obtaining high quality film material with low composition is investigated in detail. Effect of the growth interrupt in the growth process of superlattice on film optical quality is also discussed.

\section{Acknowledgments}

This work is financially supported by Science and Technology Plan Projects of the Ministry of Construction of China (2008-KT-11), the Natural Science Foundation of Tianjin (09JCYBJC04100, 08JCYBJC14800), and the National High Technology Research and Development Program of China (2006AA03Z413).

\section{References}

[1] M. Müller, T. Lehnhardt, K. Rößner, M. Hümmer, R. Werner, A. Forchel, Nanotechnol. 18, 265302 (2007).

[2] Guo-Zhi Jia, Jiang-Hong Yao, Yong-Chun Shu, Xiao-Dong Xing, Biao Pi, Appl. Surf. Sci. 2554452 (2009).

[3] Guo-Zhi Jia, Jiang-Hong Yao, Yong-Chun Shu, Xiao-Dong Xing, Biao Pi, Acta Phys. Pol. A 114, 919 (2008).

[4] G.É. Tsyrlin, V.N. Petrov, V.G. Dubrovskii, N.K. Polyakov, S.Ya. Tipisev, A.O. Golubok, N.N. Ledentsov, Semiconductors 31, 768 (1997).

[5] V. Alberts, Semicond. Sci. Technol. 8, 2125 (1993).

[6] J.S. Tsang, C.P. Lee, S.H. Lee, K.L. Tsai, H.R. Chen, J. Appl. Phys. 77, 4302 (1995).

[7] J. Schörmann, S. Potthast, D.J. As, K. Lischka, Appl. Phys. Lett. 90, 041918 (2007).

[8] E. Herbert Li, Appl. Phys. Lett. 69, 460 (1996).

[9] S.F. Wee, M.K. Chai, K.P. Homewood, J. Appl. Phys. 82, 4842 (1997).

[10] B.L. Olmsted, S.N. Houde-Walter, Appl. Phys. Lett. 60, 368 (1992).

[11] K.J. Beernink, D. Sun, D.W. Treat, B.P. Bour, Appl. Phys. Lett. 66, 3597 (1995).

[12] S.F. Wee, M.K. Chai, K.P. Homewood, W.P. Gillin, J. Appl. Phys. 82, 4842 (1997).

[13] W. Xia, C.C. Han, S.A. Pappert, S.N. Hsu, Z.F. Guan, P.K.L. Yu, S.S. Lau, Appl. Phys. Lett. 58, 625 (1991).

[14] T.Y. Tan, U. Gösele, Appl. Phys. Lett. 52, 1240 (1988). 